\title{
REDESCRIÇão de HETERopterys bahiENSIS (MALPIGHIACEAE)
}

\author{
André M. Amorim ${ }^{1,2,3}$ \& Wallace M. B. São-Mateus ${ }^{2}$
}

\begin{abstract}
Resumo
(Redescrição de Heteropterys bahiensis (Malpighiaceae)) Uma descrição completa, com ilustração e comentários taxonômicos são apresentados para Heteropterys bahiensis Nied. (Malpighiaceae), até então conhecida somente da coleção tipo. As amostras recentemente analisadas são os primeiros registros da espécie após ca. 160 anos, ampliando sua área de ocorrência no estado do Espírito Santo.
\end{abstract}

Palavras-chave: Bahia, Espírito Santo, Brasil, taxonomia.

\section{Abstract}

(Amended description of Heteropterys bahiensis (Malpighiaceae)) A complete description, with illustration and comments are provided for Heteropterys bahiensis Nied. (Malpighiaceae), known up to now only from the type collection. After a period of ca. 160 years, the recent collections are the first records for this species in the state of Espírito Santo.

Key words: Bahia, Espírito Santo, Brazil, taxonomy.

\section{INTRODUÇÃO}

Estudos taxonômicos em Heteropterys Kunth têm revelado novos táxons e indicado diversas espécies como raras e endêmicas na costa leste do Brasil (Amorim 2001, 2002, 2003, 2004 e 2005). Esse artigo é uma contribuição ao andamento da revisão de Heteropterys e fornece uma descrição complementar e uma ilustração para Heteropterys bahiensis. Essa espécie só era conhecida do material-tipo, o qual só apresenta a inflorescência com flores já em avançado estádio de desenvolvimento, o que dificultava o conceito morfológico desse táxon.

\section{Material e Métodos}

Foram utilizados coleções depositadas nos herbários CEPEC, CVRD, F, G, IAN, INPA, MBM, MBML, MICH, NY, RB, SP e UPCB. Coletas de material botânico foram executadas nas supostas áreas de ocorrência da espécie, abrangendo os estados da Bahia e Espírito Santo. Na descrição, os caracteres qualitativos e quantitativos foram baseados exclusivamente no material examinado e sempre que possível, mensurações foram complementadas a partir de material vivo e/ou fixado em álcool etílico 70\%, principalmente com relação aos caracteres florais. As ilustrações de detalhes morfológicos foram feitas pelo primeiro autor e utilizou-se câmara clara acoplada a estereomicroscópio Olympus $\mathrm{SZH}$ 10. A representação do androceu corresponde à seguinte ordenação: o segundo estame da direita é oposto à pétala posterior e o quarto estame da esquerda é oposto à sépala anterior.

\section{Resultados e Discussão}

Heteropterys bahiensis Nied., Arbeiten Bot. Inst. Königl. Lyceum Hosianum Braunsberg 2: 26. 1903. TIPO: BRASIL. BAHIA: Blanchet 1458 (holótipo G; fotos CEPEC, F, IAN, INPA, $\mathrm{MICH}, \mathrm{NY}$ ).

Fig. 1

Lianas 3-7 m alt.; ramos 0,5-1 cm diâm. na base, glabros, com lenticelas esparsas. Folhas opostas; pecíolo 0,9-2 mm compr., glabro, eglanduloso; estípulas presentes acima da base dos pecíolos como diminutas protuberâncias, $0,1-0,2 \mathrm{~mm}$ compr., frequentemente encobertas por tricomas, prematuramente caducas; lâmina $(7,7-) 9,5-$ $18,7(-24) \times(2,5-) 3,4-6,4 \mathrm{~cm}$, membranácea a cartácea, oblonga, oblongo-lanceolada, obovada-oblonga a largamente lanceolada,

Artigo recebido em 05/2008. Aceito para publicação em 02/2009.

${ }^{1}$ Universidade Estadual de Santa Cruz, Departamento de Ciências Biológicas, Ilhéus, 45650-970, BA, Brasil.

${ }^{2}$ Herbário André Maurício V. de Carvalho (CEPEC), Ilhéus, 45650-970, BA, Brasil.

${ }^{3}$ Autor para correspondência: aamorimm@terra.com.br 
base obtusa ou levemente cuneada, ápice agudo, obtuso, arredondado ou raro acuminado, margens inteiras ou levemente sinuadas, principalmente nas folhas jovens; face abaxial da lâmina apresentando uma a duas glândulas largas em cada lado da base próximo à nervura central e uma fileira de glândulas submarginais da base ao ápice; face abaxial e adaxial glabras; nervuras laterais evidentes e retículo inconspícuo na face abaxial. Inflorescência em panícula bracteosa, laxa, terminal ou raramente axilar, pêndula, esparsamente serícea, 4-7 cm compr., ramificação primária 4-6, 2,5-4,2 cm compr., ramificação secundária 2-4, ca. 1,5 cm compr., as últimas unidades em corimbo ou umbela 4-6-flora subtendidas por 2-4 flores ou não; bráctea da inflorescência abruptamente reduzida a $1,2-2,2 \times 0,5-0,8 \mathrm{~cm}$, oblonga a oval, margens inteiras, 4-glandulosa na base, cada glândula ca. 0,5 mm diâm.; pedúnculo floral 0,8-1,2 cm compr., uniformemente delgado, esparsamente seríceo; bráctea ca. 1,5 × $1 \mathrm{~mm}$, oval, escamiforme, eglandulosa, inserida na base do pedúnculo, face abaxial serícea; bractéolas como a bráctea porém menores, inseridas na articulação entre o pedúnculo e o pedicelo, com 2-3 glândulas na base; pedicelo 0,8-1,2 cm, esparsamente seríceo, uniformemente delgado. Sépalas 1,2-1,4×1,3-1,6 mm, triangulares ou agudas no ápice, apressas aos filetes, face abaxial serícea, adaxial glabra, todas biglandulosas, glândulas 1,8-2,5 mm compr. Pétalas expostas no botão floral, amarelopálidas, glabras em ambas as faces; pétalas laterais reflexas, unha ca. 1,7 mm compr., limbo arredondado, 2,7-3,1 × 1,3-2,3 mm, margem inteiras a levemente erosa-denticulada; pétala posterior sub-ereta, unha ca. 1,9 mm compr., limbo 1,9-2,9 × 1,5 mm, margem glandulosodenticulada. Estames iguais entre si; filetes esparsamente seríceos na face abaxial, 1,7-2 $\times 0,2-0,4 \mathrm{~mm}$, conatos ca. $1 / 2-1 / 3$ na porção proximal; anteras 1,2-1,3 mm compr., iguais entre si, ressupinadas na antese, glabras; conectivo uniformemente escuro. Ovário ca. 1,6 mm compr., densamente seríceo; estiletes 1,5-1,7 mm compr., de mesmo tamanho do androceu, levemente divergentes na porção distal, o anterior e os dois posteriores com as faces do estigma voltadas para o centro da flor, glabros, dorsalmente truncados no ápice, estigma lateral. Samarídeo róseo quando maduro, 5,9-8,7 cm compr., disposição oblíqua, esparsamente seríceo a glabrescente; ala dorsal 5,1-8 × 2,1-3,1 mm, margem inferior espessada até o núcleo seminífero; núcleo 816 mm diâm., levemente triangular, lateralmente liso, sem alas laterais ou crestas, nervuras longitudinais proeminentes.

Material Examinado: BRASIL. ESPÍRITO SANTO: Linhares, Reserva Florestal da Cia. Vale do Rio Doce: Estrada do Flamengo, 20.VI.2000, fr., C. B. Costa 327 (CEPEC, CVRD, MICH); Estrada da Gávea, RFL 01/80, Bloco 1, 25.I.2001, fl., D. A. Folli 3814 (CEPEC, CVRD, MICH, SP); Nova Venécia, APA da Pedra do Elefante: Pedra da Torre, 18.II.2008, fl., A.M. Amorim et al. 7173 (CEPEC, MBM, MBML, NY, RB, SP, UPCB); Trilha principal na Mata da Fazenda Santa Rita, 16.VII.2008, fr., A.M. Amorim et al. 7498 (CEPEC, MBML, RB); Pinheiros, Santa Rita, 130msm, 1.II.2008, fl., L. Kollmann \& L. Magnago 10533 (CEPEC, MBML); Santa Teresa, Goiapaba-Açu, 29.VIII.2001, fr., L. Kollmann \& E. Bausen 4410 a (CEPEC, MBML).

Heteropterys bahiensis é aqui redescrita porque na obra original (Niedenzu 1903) não são detalhados os caracteres florais e do fruto dessa espécie. Heteropterys bahiensis é claramente relacionada às séries Metallophyllis/Madarophyllis Nied. pela seguinte combinação de caracteres: face abaxial da lâmina foliar com uma fileira de glândulas submarginais da base ao ápice, pedicelo pedunculado com as bractéolas inseridas na articulação entre o pedúnculo e o pedicelo, pétalas amarelo-pálidas expostas no botão floral, estames iguais entre si, filetes seríceos na face abaxial e núcleo do samarídeo sem alas laterais ou crestas.

Assemelha-se a Heteropterys nitida (Lam.) H.B.K. pela forma e dimensões da lâmina foliar e da flor. No entanto, $H$. bahiensis é diferenciada pela lâmina glabra na face abaxial, apresentando glândulas largas na base, inflorescência bracteosa, pedúnculo e pedicelo uniformemente delgado e desenvolvido, e núcleo 


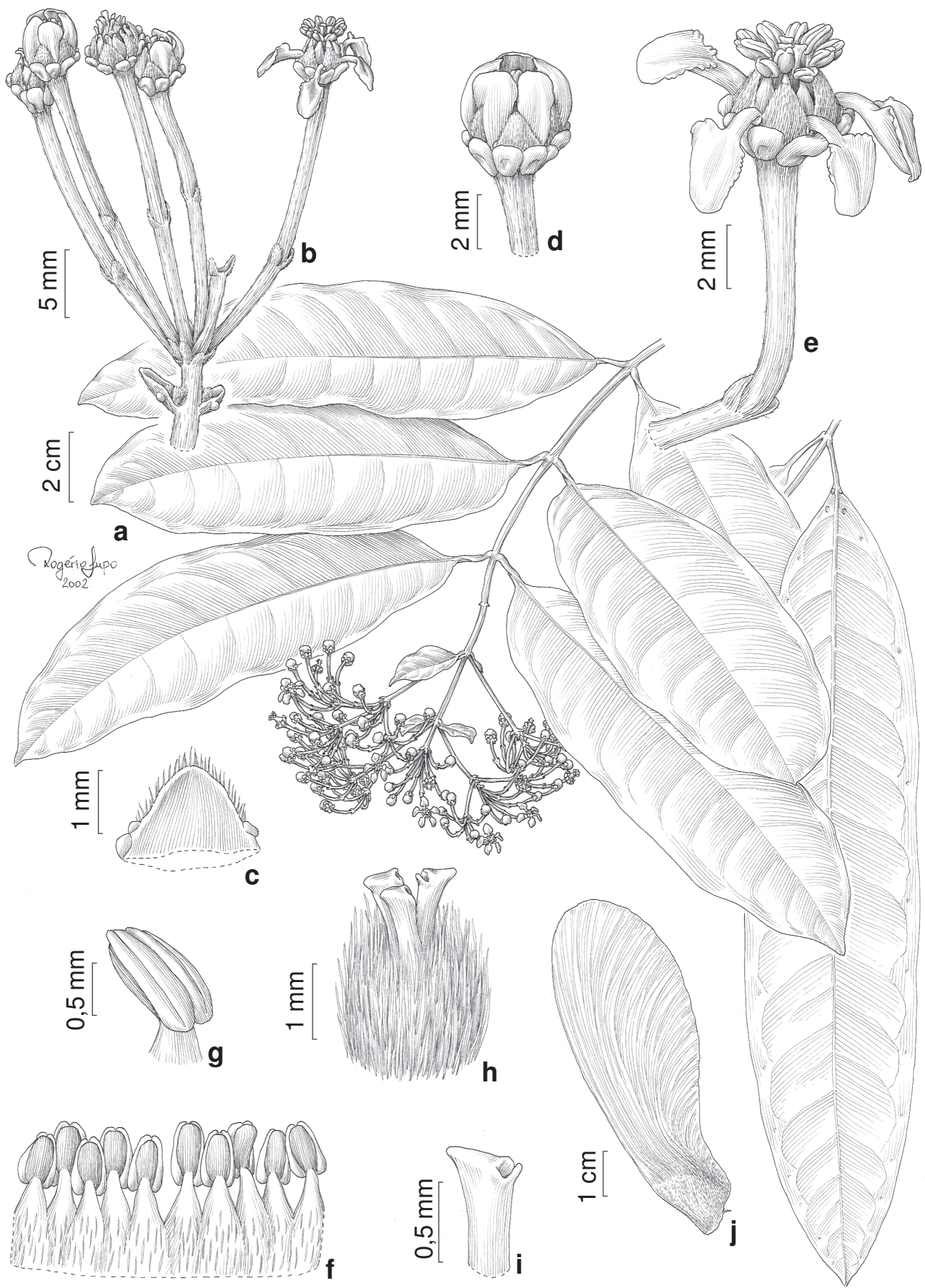

Figura 1 - Heteropterys bahiensis Nied. - a. ramo com inflorescência e detalhe da face abaxial da lâmina, evidenciando as glândulas; b. detalhe da inflorescência; c. bractéola, face adaxial; d. botão floral; e. flor, vista lateral; f. androceu, vista abaxial; g. detalhe da antera; h. gineceu, estilete anterior a direita; i. detalhe do ápice do estilete anterior; j. samarídeo, vista lateral. (a-i Folli 3814; j Kollmann 4410a)

Figure 1 - Heteropterys bahiensis Nied. - a. flowering branch and detail of the abaxial surface of the leaf lamina, showing glands; b. detail of inflorescence; c. bracteole, adaxial surface; d. flower bud; e. flower, lateral view; f. androecium, abaxial view; g. detail of anther; h. gynoecium, the anterior style to right; i. detail of apex of the anterior style; j. samara, lateral view. (a-i Folli 3814; j Kollmann 4410a) 
do samarídeo levemente triangular ( $v s$. lâmina com indumento densamente metálico seríceo na face abaxial, base da lâmina eglandular, inflorescência frondo-bracteosa, pedicelo alargando-se em direção ao ápice e núcleo do samarídeo arredondado a oval). Outras espécies com a qual $H$. bahiensis compartilha afinidades morfológicas, especialmente relacionadas à forma das inflorescências e estrutura floral são $H$. megaptera A. Juss., conhecida de poucas coleções entre os estados do Rio de Janeiro e Bahia, e H. sincorensis W.R. Anderson, uma espécie endêmica de campos rupestres na Bahia.

Heteropterys bahiensis ocorre no estado do Espírito Santo em floresta ombrófila densa montana, floresta ombrófila sob tabuleiro e floresta estacional semidecidual onde é encontrada no sub-bosque, preferencialmente em áreas próximas a córregos e rios. Na Bahia, de onde é indicada a proveniência do materialtipo, não foi feito até o momento nenhum registro adicional desse táxon. As recentes coleções de $H$. bahiensis são os primeiros registros em ca. 160 anos e evidenciam o endemismo e o forte grau de ameaça que a espécie apresenta.

\section{Agradecimentos}

Agradecemos a Cristina Bestetti Costa, por chamar a atenção do primeiro autor sobre essa espécie, a Rogério Lupo, pela ilustração e aos curadores dos Herbários pelo acesso as coleções analisadas. A visita aos herbários e as localidades no estado do Espírito Santo foi financiada pela Fundação O Boticário de Proteção a Natureza (Proposta 200720074) e pelo National Science Foundation (Proposta 9972116).

\section{Referencias Bibliográficas}

Amorim, A. M. 2001. Two new species of Heteropterys (Malpighiaceae) from southeastern Brazil. Contributions from University Michigan Herbarium 23: 29-34.

Amorim, A. M. 2002. Five new species of Heteropterys (Malpighiaceae) from Central and South America. Brittonia 54(4): 217-232.

Amorim, A. M. 2003. The anomalousstemmed species of Heteropterys subsec. Aptychia (Malpighiaceae). Brittonia 55(2): 127-145.

Amorim, A. M. 2004. A new species of Heteropterys (Malpighiaceae) from the semi-deciduous forests of Bahia, Brazil. Brittonia 56(2): 70-74.

Amorim, A. M. 2005. Heteropterys jardimii (Malpighiaceae), uma nova espécie para a Bahia, Brasil. Rodriguésia 56(87): 175-178.

Niedenzu, F. 1903. De genere Heteropteryge. Arbeiten Bot. Inst. Königl. Lyceum Hosianum Braunsberg 2: 3-56. 